\title{
The influence of Pulsed Laser Powder Bed Fusion Process Parameters on Inconel 718
}

\section{Material Properties}

\author{
Konstantinos Georgilas ${ }^{1,2}$, Raja H.U. Khan ${ }^{3}$, Mehmet E. Kartal ${ }^{1}$ \\ ${ }^{1}$ University of Aberdeen, School of Engineering, Aberdeen, AB24 3UE, UK \\ ${ }^{2}$ National Structural Integrity Research Centre, Cambridge, CB21 6AL, UK \\ ${ }^{3}$ TWI Ltd., Cambridge, CB21 6AL, UK
}

\section{Abstract}

In this work, the effect of pulsed laser used during the powder bed fusion (L-PBF) additive manufacturing (AM) process on Inconel 718 (IN718) material properties has been investigated. Argon gas atomised (AGA) IN718 powder is characterised in terms of flow, density, particle size distribution and morphology. Powder shows mostly spherical morphology with Hausner ratio of 1.17 indicating good flow characteristics. Density optimisation trials are carried out by varying laser power and exposure time. Fabricated samples are characterised in terms of porosity by area fraction analysis using light microscopy and volume fraction analysis using X-ray microcomputed tomography (micro-CT). Minimum porosity of $0.16 \%$ is achieved for laser power of $200 \mathrm{~W}$ and exposure time of $110 \mu$ s. Microstructural analysis using the Electron Backscatter Diffraction (EBSD) technique shows limited columnar grain structure in the $\mathrm{Z}$ direction and more equiaxed type grains in the $\mathrm{XY}$ direction (normal to the $\mathrm{Z}$ direction). Tensile test results show $754 \mathrm{MPa}$ yield strength, $1070 \mathrm{MPa}$ ultimate tensile strength and $24 \%$ elongation. Finally, hole drilling residual stress measurements show increase from $\sim 0 \mathrm{MPa}$ to over $450 \mathrm{MPa}$ in tensile stress up to a depth of $1 \mathrm{~mm}$ from the top surface of the as-build LPBF IN718 sample. It has been found that laser pulsing produces higher homogeneity in grain structure and better mechanical properties than that by the continuous laser method. 
Keywords: powder methods, nickel alloys, grains and interfaces, stress/strain measurements, characterization

\section{Introduction}

Additive manufacturing (AM) is a family of novel manufacturing processes that allows for fabrication of parts from 3D CAD models [1]. AM has shown great potential and growth over the last decade and is expected to further revolutionise manufacturing of complex engineering parts [2]. AM has been recently used with a variety of engineering materials including polymers, metals and ceramics [1,2]. Notably, industry has shown a desire to manufacture metallic engineering components using expensive and hard-to-process materials such as titanium and nickel base superalloys [2].

The laser powder bed fusion (L-PBF) AM method is used to fabricate metallic engineering components using powder feedstock materials. The L-PBF process broadly involves following steps: metallic powder is spread on the top of a build substrate platform creating a 'powder bed'; the powder bed is scanned by a heat source according to the 2D slices of the CAD model; the heat source melts the powder which subsequently solidifies, creating a 2D layer of the object being manufactured; and finally the platform moves downwards, and a new powder bed is created. By repeating the process, 2D layers are added and consolidated until a fully 3D component emerges [1]. Figure 1 shows a schematic of the L-PBF process.

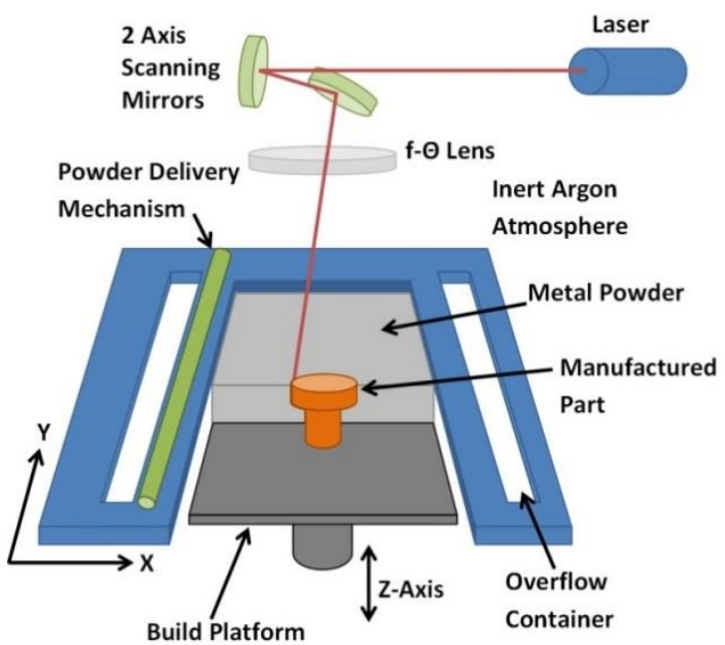


Figure 1: Schematic of L-PBF Process.(Courtesy of TWI Ltd.)

The fabricated metallic material is subjected to a complex cycle of heating and cooling during the L-PBF process [3]. Prior research has shown that this complex thermal history leads to various issues arising in deposited material. These issues include defects (lack of fusion, porosity etc.) [4-7], accumulation of residual stresses [8-10] and microstructural inhomogeneity leading to anisotropy in the mechanical properties [11,12]. Density of deposited material varies with the variation of L-PBF process parameters and for each 'material machine' combination, development work is necessary to maximise it $[4,13]$. Residual stresses are usually generated due to the melting and rapid solidification during the manufacturing process $[9,13]$. Thermal residual stresses can be minimised by preheating the build plate during the manufacturing process [13] or by performing post-thermal treatments such as stress relieving and hot isostatic pressing [14].

Inconel 718 (IN718) is a nickel base superalloy which possesses excellent corrosion resistance, high temperature (up to $650^{\circ} \mathrm{C}$ ) strength and the fracture \& fatigue properties [15]. It is extensively used in various industrial sectors including aerospace, oil \& gas and power generation $[15,16]$. IN718 is a precipitation hardened material that contains substantial amounts of other alloying elements including iron $(\mathrm{Fe})$, niobium $(\mathrm{Nb})$ and chromium $(\mathrm{Cr})$. The main phase of IN718 is an austenitic matrix phase formed by Ni, called the $\gamma$ (gamma) phase. Within the matrix, secondary phases can precipitate called gamma prime $\left(\gamma^{\prime}\right)-\mathrm{Ni}_{3}(\mathrm{Al}, \mathrm{Ti})$ and metastable gamma double prime $\left(\gamma^{\prime \prime}\right)$ - $\mathrm{Ni}_{3} \mathrm{Nb}$ with tetragonal, space centred crystal structure $\left(\mathrm{D}_{22}\right)$. These precipitates increase strength of the material and are stable up to $720^{\circ} \mathrm{C}$. However, when the material is exposed to temperatures higher than $720^{\circ} \mathrm{C}$, deleterious delta

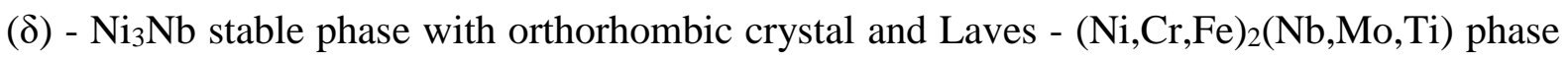
transformation occurs, leading to the decreased its mechanical properties $[15,16]$. 
There is currently an industrial desire to produce safety critical IN718 components using the L-PBF manufacturing process. However, combination of the complex thermal history caused by the L-PBF process and the complicated metallurgy of IN718 leads to parts that do not have the desirable microstructure [17-20]. They also exhibit highly anisotropic microstructure which usually results in large scatter band in the mechanical properties [20,21]. Typically, the columnar type microstructure is observed along the $\mathrm{Z}$ direction [20]. Whereas, in the $\mathrm{XY}$ direction (transverse to the $\mathrm{Z}$ direction) more random equiaxed microstructure is observed [20]. It is well known that the texture in microstructure depends on numerous factors such as thermal gradient and the solidification velocity.

In order to control these aforementioned factors and to create tailor-made 'graded' microstructures [5,22], various methods have been developed. One of the most promising techniques is a pulse beam approach during manufacturing. Pulsing is a method in which the electric current injected into the laser diodes is switched on and off rapidly [23,24]. Hence, the laser is emitted in 'pulses' of light lasting from a few milliseconds to a few picoseconds [24]. Due to this pulsing effect the powder bed is not scanned in a continuous line but as a series of overlapping circles.

Using a pulsing heat source alters the heating and especially the cooling characteristics of the PBF process. In electron beam (EB)-PBF when the electron beam is pulsed to fabricate IN718 material it has shown promise with regards to achieving desirable isotropy in microstructure $[25,26]$. However, during L-PBF the effect of a pulsing laser source has not been thoroughly examined and any work done to date has been focused on aluminium and titanium alloys $[23,24]$. A pulsating heat source has been shown to lead to a less columnar grain structure in aluminium alloys due to significantly higher cooling rates [24,27]. Similar material response has been found in titanium alloys with the higher cooling rates leading to lower number of columnar grains $[24,28]$. Hence, there is a gap in the state-of-the-art to see the effect of a pulsed 
laser heat source on the microstructure and mechanical properties of L-PBF IN718 structure and the possibility of achieving higher homogeneity in grain structure due to higher cooling rates.

The objectives of the present work are to:

- Determine the suitability of the supplied argon gas atomised (AGA) IN718 feedstock powder for the L-PBF process.

- Perform density optimisation trials with the pulsed L-PBF process by varying the laser power and exposure time process parameters and to determine the porosity using both area and volume fraction analyses.

- Determine the tensile properties of L-PBF IN718 manufactured using optimised process parameters in three different build orientations.

- Measure residual stresses by the hole drilling method in L-PBF IN718 samples manufactured using optimised process parameters.

\section{Material and Experimental Procedures}

2.1 Material and manufacturing

Argon gas atomised IN718 powder with a stated particle size of $15-45 \mu \mathrm{m}$ and below $63 \mu \mathrm{m}$ was acquired from LPW technology (Cheshire, UK).

Specimens were manufactured using an AM250 machine built by Renishaw (Gloucestershire, UK). The machine was equipped with a $200 \mathrm{~W}$ fibre laser working in pulsed wave mode. Specimens were designed in CAD software and sectioned into STL files. Manufacturing took place in a protective argon atmosphere, with no substrate preheating.

A machine equipped with a pulsed mode laser, works by illuminating a point with the desired laser power for a specific exposure time before moving to the next point and repeating the process. The AM250 machine has numerous parameters that can be varied including layer thickness, laser power, exposure time, hatch spacing, point distance etc.. Two main parameters 
were varied during this work: pulse laser power and exposure time. These were selected as the controlling parameters because they regulate the amount of energy that is inputted into the powder bed. Virgin powder was used for each production run. Unless otherwise specified all the samples were offset from the build plate using support structures.

\subsection{Sample preparation}

A series of 16 cubes of $10 \mathrm{~mm}^{3}$ size, were produced to determine the suitable L-PBF process parameters showing maximum density in the build material. Moreover, these samples were used to investigate the defects, porosity as well as microstructural inhomogeneity.

The cubes were manufactured by varying the laser power from 170 to $200 \mathrm{~W}$ and the exposure time from 90 to $120 \mu$ s. Layer thickness was $60 \mu \mathrm{m}$ as suggested by the machine manufacturer as a good compromise between the required energy and manufacturing speed. The point distance was $60 \mu \mathrm{m}$ and the hatch spacing was $140 \mu \mathrm{m}$. Between each layer, the scanning pattern was rotated by $67^{\circ}$.

In order to investigate the effect of grain anisotropy, the L-PBF cubes were sectioned in the longitudinal build $(\mathrm{Z})$ and traverse $(\mathrm{XY})$ directions as shown in Figure 2. The $\mathrm{Z}$ and $\mathrm{XY}$ samples were hot mounted using conductive Bakelite to form a single disk, for each set of parameters. Each sample disk was metallographically prepared using silicon carbide ( $\mathrm{SiC})$ grinding papers of 600,1200 and 2500 grit. Final polishing was carried out using $3 \mu \mathrm{m}, 1 \mu \mathrm{m}$ and $0.25 \mu \mathrm{m}$ diamond suspensions and colloidal silica nanoparticle suspension solution.

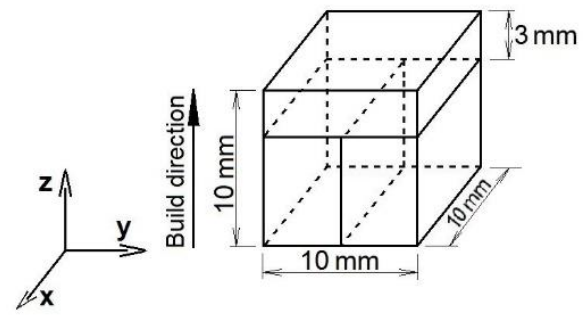

Figure 2: Schematic cutting plan for L-PBF IN718 cube samples. 
Near net-shape cylindrical tensile samples were produced at three different orientations, with the gauge length vertical, horizontal and at 45 degrees to the built plate. A total of nine samples were produced, three in each orientation. The length of each sample was $60 \mathrm{~mm}$ with $8 \mathrm{~mm}$ diameter. Six specimens for residual stresses measurement using the incremental hole drilling method were manufactured. The dimensions of each specimen were $30 \mathrm{~mm}$ x $30 \mathrm{~mm}$ x $10 \mathrm{~mm}$. The tensile and hole drilling samples were manufactured using the down-selected parameters that maximised density.

\subsection{Powder characterisation}

To determine the suitability of the IN718 powder for the L-PBF process it was characterised in terms of chemical composition (ISO 7524 [29],7525 [30]), powder size distribution (ASTM B822-17 [31]), flowability (ASTM B213-17 [32]), apparent density (ASTM B212-17 [33]) and tap density (ASTM B527-15 [34]). Using standardised testing results the Hausner ratio was calculated. The Hausner ratio is an empirical metric of flowability, which is calculated by dividing tap density by the apparent density. Samples of the powder were also metallographically prepared to observe surface morphology and powder internal structure by using a using a Zeiss Sigma field emission gun scanning electron microscope (FEG-SEM) (Cambridge, UK). PSD analysis was carried out using a Mastersizer 3000 equipment manufactured by Malvern Panalytical (Malvern, UK). Flowability, apparent density and packing density measurements were carried out using a PowderFlow kit supplied by LPW technology.

\subsection{Porosity measurement \& texture analysis}

The porosity of the L-PBF samples was measured with two different methods, area fraction and volume fraction analyses. For the former analyses, a representative light micrograph based method described in ASTM E2109-01 (2014) [35] was employed on polished samples in both the $\mathrm{Z}$ and $\mathrm{XY}$ orientations. Each polished sample disk was observed using an Olympus (Essex, 
UK) BX51M light microscope. For each of 16 sample disks, greyscale micrographs were acquired at a magnification of $10 \mathrm{X}$ with a constant light level and exposure time. Each micrograph was 2048x1464pixels equivalent to $1.1 \times 0.822 \mathrm{~mm}^{2} .64$ micrographs were acquired from the $\mathrm{XY}$ direction and 40 micrographs from the $\mathrm{Z}$ direction. The micrographs were then processed using ImageJ processing software. Each micrograph was converted into black and white using a thresholding tool. Pores were converted into black pixels. The percentage of black pixels versus the total number of pixels, for each micrograph was determined. Porosity was then calculated by averaging the percentages of black pixels of the micrographs for each set of parameters.

For volume fraction analyses, micro-CT scans were performed by using a lab-based X-ray micro-CT scanner at the University of Aberdeen, Zeiss XRADIA-410 having a minimum spatial resolution of $0.9 \mu \mathrm{m}$ and minimum voxel size of $0.1 \mu \mathrm{m}$. As the material used in this study has a high formula unit $(Z)$ value, the duration of the scan time (30 hours per sample) was significantly high, despite voltage of $140 \mathrm{kV}$, power of $10 \mathrm{~W}$ and a binning mode of 4 . Since cost and time involved were high, not all of 16 samples were scanned. For this purpose, samples with lowest porosity were down selected. The region of interest was the centre of each sample and a cylinder $(\varnothing 2 \mathrm{~mm} \times 2 \mathrm{~mm})$ was scanned and reconstructed. Note that greater detail about the infrastructure and reconstruction can be found elsewhere [36]. The voxel size was $4 \mu \mathrm{m}$. The resulting data was post-processed using Avizo software by Fisher Scientific (Oregon, USA). Processing of the data involved using a threshold to convert porosity into black voxels. Total volume of voxels was calculated for each sample and 3D rendered to determine the distribution of porosity.

In addition to light microscopy and micro-CT based fraction analyses, texture analysis was carried out on the polished sample that had the lowest porosity by electron backscatter diffraction (EBSD). The map was acquired using a Nordlys EBSD detector manufactured by 
Oxford Instruments (High Wycombe, UK). Processing of maps was performed on Channel5 software also supplied by Oxford Instruments. Maps were acquired with an accelerating voltage of $30 \mathrm{kV}$. The step size was $0.65 \mu \mathrm{m}$.

\subsection{Tensile testing}

L-PBF IN718 cylindrical tensile samples were CNC machined from a diameter of $8 \mathrm{~mm}$ to a diameter of $4 \mathrm{~mm}$ on the gauge length as stipulated by the ASTM E8-16a standard [37]. Samples were marked with a $16 \mathrm{~mm}$ gauge length to calculate plastic elongation after failure. The yield testing was carried out on Instron (Massachusetts, USA) tensile testing machines with a strain rate control of 0.015 strain/min and using a dual averaging extensometer. After yield the strain rate was increased to 0.4 strain/min until fracture.

\subsection{Incremental hole drilling residual stresses measurements}

The incremental hole drilling method was used to determine in-plane residual stresses in the L-PBF samples. Measurements were carried out according to ASTM standard E837-13a.A total of six specimens were hole drilled, three with support structures (Specimens 1-3) and three build without support structures (Specimens 4-6).

Type 'A' strain gauge rosette was used at the centre of the top surface of each sample. The rosette consists of three strain gauges each connected to a desktop computer through an amplifier at a voltage of $10 \mathrm{~V}$. This positioning of the rosette leads to the measurement of the $\sigma_{\mathrm{xx}}$ and $\sigma_{\mathrm{yy}}$ in-plane stresses as well as the $\tau_{\mathrm{xy}}$ shear stress. Due to porosity present in the L-PBF samples, the hole cannot be drilled using regular drill bits as these can frequently break when they encounter a pore due to deflection. Hence, the hole was drilled through the rosette using an AJ-1 air abrasion machine made by Texas Airsonics (Texas, USA). The hole is drilled by using pure silica sand propelled by a $551 \mathrm{kPa}$ compressed air stream through a $2 \mathrm{~mm}$ diameter orifice abrading IN718 material to create a $2 \mathrm{~mm}$ diameter hole. It is not possible to control the hole depth using air abrasion. Hence, steps were achieved by drilling in two (2) minute intervals 
until depth reached $1 \mathrm{~mm}$. Depth and diameter of the hole at each step were determined by a calibrated graduated focusing scope which can measure the focusing distance in thousandths of an inch. Measurements were processed using Eval 7 software by SINT technology (Florence, IT). The residual stresses were assumed to be non-uniform and integral method was used for the calculation [38].

\section{Results and Discussion}

\subsection{Powder characterisation}

Table 1 shows the chemical composition of IN718 powder as analysed by AMG Superalloys (Rotherham, UK).

Table 1: Chemical composition (wt.\%) of IN718 powder

\begin{tabular}{|c|c|c|c|c|c|c|c|c|c|c|}
\hline Element & Ni & Cr & Fe & Nb & Mo & Ti & Al & Co & C & O \\
\hline Weight \% & 53.32 & 18.99 & 18.01 & 5.01 & 3.04 & 0.91 & 0.46 & 0.06 & 0.05 & 0.022 \\
\hline
\end{tabular}

The powder was found to have good flowing and density properties. Table 2 shows flowability and density data. Flowability was measured at $12.33 \mathrm{~s}$ per $50 \mathrm{~g}$ of powder. Observation of powder during the test showed that powder flow was consistent and smooth without stoppages and without any clump formation. Hausner ratio was found to be 1.17 for this powder. Hausner ratio values below 1.25 have been linked with good flowability properties. Density measurement data showed that the apparent density is $4.55 \mathrm{~g} / \mathrm{cm}^{3}$ or a packing density of $\sim 55 \%$ and the tap density is $5.3 \mathrm{~g} / \mathrm{cm}^{3}$.

Table 2: Flowability, apparent \& tap density and Hausner ratio for IN718 powder

\begin{tabular}{|c|c|c|c|c|}
\hline Metal Powder & $\begin{array}{c}\text { Flowability } \\
(\mathbf{s} / \mathbf{5 0 g})\end{array}$ & $\begin{array}{c}\text { Apparent } \\
\text { density }\left(\mathbf{g} / \mathbf{c m}^{\mathbf{3}}\right)\end{array}$ & $\begin{array}{c}\text { Tap density } \\
\left(\mathbf{g} / \mathbf{c m}^{\mathbf{3}}\right)\end{array}$ & $\begin{array}{c}\text { Hausner Ratio } \\
\left(\mathbf{A D}_{\mathbf{H}} / \mathbf{P}_{\mathfrak{t}}\right)\end{array}$ \\
\hline LPW IN718 & 12.33 & 4.55 & 5.3 & 1.17 \\
\hline
\end{tabular}


In terms of powder size distribution (PSD), the powder is suitable for the L-PBF process. PSD of the IN718 powder was found to be slightly higher than nominal size of $15-45 \mu \mathrm{m}$ but lower than a maximum $63 \mu \mathrm{m}$. Results obtained from the PSD analysis are shown in Table 3 . The PSD analysis is typically reported through $D_{v} x$ values. These values represent the diameter below which $x$ percent of the volume of the powder particles were found. Hence, $\mathrm{D}_{\mathrm{v}} 10$ means that $10 \%$ of the powder particles have a diameter smaller than $29 \mu \mathrm{m}$ whereas $\mathrm{D}_{\mathrm{v}} 90$ means that $10 \%$ of the particles have a diameter higher than $52 \mu \mathrm{m}$.

Table 3: Light scattering PSD analysis data for AGA IN718 powder

\begin{tabular}{|l|c|c|c|c|c|c|}
\hline & Result 1 & Result 2 & Result 3 & Average & Allowable & Fail/Pass \\
\hline $\boldsymbol{D}_{\boldsymbol{v}} \mathbf{1 0}(\boldsymbol{\mu \mathbf { m }})$ & 29.0 & 29.1 & 29.2 & $\mathbf{2 9}$ & $15-30$ & Pass \\
\hline $\boldsymbol{D}_{v} \mathbf{5 0}(\boldsymbol{\mu \mathbf { m }})$ & 38.8 & 38.9 & 39.0 & $\mathbf{3 9}$ & $30-45$ & Pass \\
\hline $\boldsymbol{D}_{\boldsymbol{v}} \mathbf{9 0}(\boldsymbol{\mu \mathbf { m }})$ & 51.5 & 51.6 & 51.7 & $\mathbf{5 2}$ & $45-60$ & Pass \\
\hline
\end{tabular}

Whole powder micrograph shows that the majority of particles are spherical in shape and thus suitable for the L-PBF process. Figure 3 shows morphology of both whole (a) and cross-section (b) of IN718 powder. However, some number of irregularly shaped particles can also be observed. These include satellites, splat caps, fragmented particles and elongated particles (shown by arrows). These irregular particles are produced during the atomisation process and thus their presence is acceptable. Powder cross-section micrograph shows that most of the powder particles are spherical. However, a particle at the centre of the image shows porosity inside the powder because argon gas can get trapped inside the particles during the atomisation process.

Irregularly shaped particles can have highly differing dimensions impacting the measured PSD of the powder. This occurs because the differing dimensions allow them to pass through sieves used to separate powder size ranges after the manufacturing process. During PSD analysis some of these particles will scatter light along the larger dimension. Thus, they are measured 
as being bigger than the stated value of $<63 \mu \mathrm{m}$ and due to the limitations of the technique they will be reported as larger than their actual size. Hence, the reported PSD range is slightly overestimated.

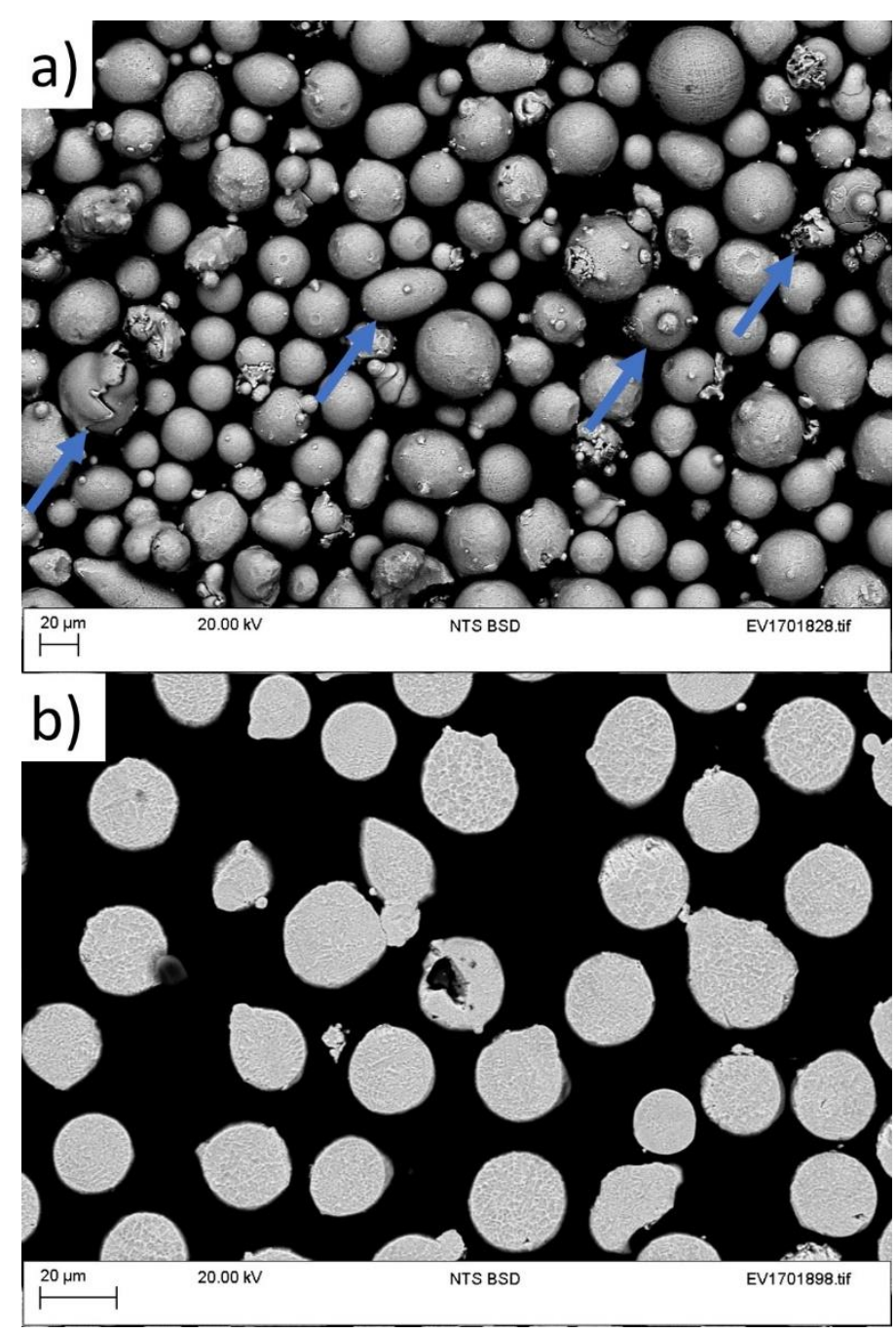

Figure 3: SEM micrographs of whole powder (a) and polished cross-section (b). Arrows point out irregular particles present in the powder

\subsection{Porosity measurement}

The area fraction analysis results are shown in Figure 4 which is a compilation of micrographs taken from samples in the XY direction. According to these measurements, porosity varies from $5.33 \%$ for sample A1 to $0.16 \%$ for sample D3. It is apparent that increasing either laser power or exposure time leads to a decrease in porosity. Hence increasing the laser power from 
$170 \mathrm{~W}$ to $200 \mathrm{~W}$ for a constant exposure time of $90 \mu$ s leads to a decrease in porosity from $5.33 \%$ to $1.92 \%$ for samples A1 to A4. Similarly, increasing the exposure time from $90 \mu$ s to $120 \mu$ s for a constant laser power of $170 \mathrm{~W}$ causes a drop, in porosity from $5.33 \%$ to $1.1 \%$ for samples A1 to D1. Increasing both parameters at the same time leads to a rapid decrease in porosity. However, after a certain point further increase leads to a slight increase in porosity as can be seen between samples D3 and D4. The micrographs also show the shape of porosity. For high porosity values $(>1 \%)$ the shape is irregular and shows to be arranged in lines, probably coinciding with scan lines. For low porosity $(<1 \%)$ the shape of the pores changes to be circular and does not follow any discernible pattern. Elongated pores are a result of lack of fusion defects within and between layers due to insufficient heat input to completely melt the powder. Circular pores are caused by argon gas being trapped within the material.

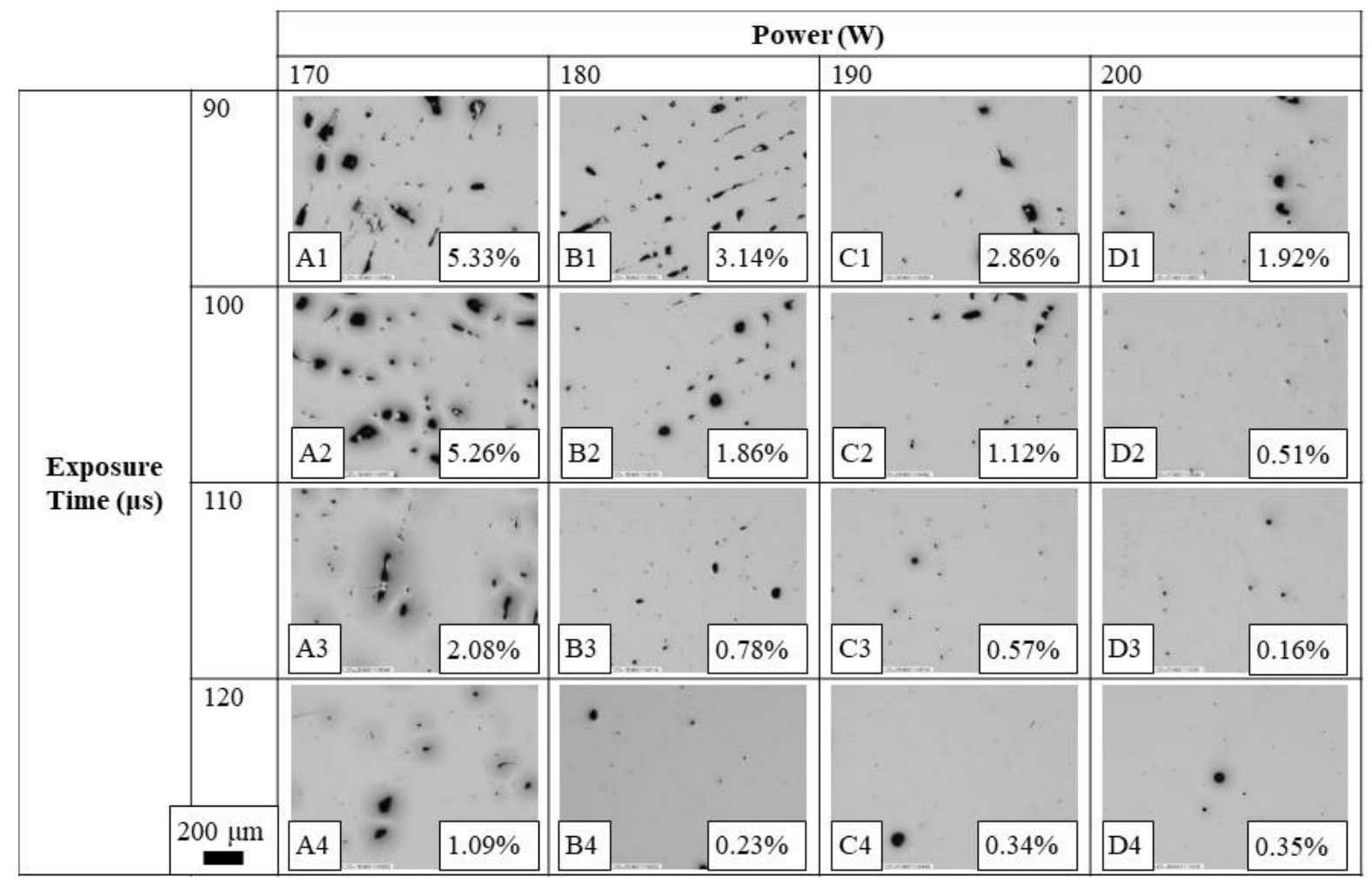

Figure 4: Light micrographs showing porosity in L-PBF IN718 samples in XY direction, porosity varied by varying laser power and exposure time 
Laser power and exposure time can individually affect the amount of energy inputted in the powder bed. Hence, a concurrent increase in both laser power and exposure time cause more thorough melting of the powder bed. However, increasing the parameters separately is not enough to melt the powder completely, leading to unmelted or partially melted powder particles, which then create porosity due to lack of fusion. Increasing both parameters at the same time leads to amplified energy input, which can completely melt the powder layer exposed to laser beam and hence minimise porosity (D3). Further increase in exposure time leads to a slight increase in porosity (D4). The increase in porosity for the parameters of sample D4 is possibly an effect of increased sublimation or boiling of lighter elements in the melt pool, such as aluminium [39].

The above interpretation is supported by the shape of the porosity. Irregular pores are formed due to improper and incomplete melting of the powder bed. Circular pores are formed as a result of entrapment of argon gas which tends to get trapped during the solidification process and leave rounded pores. As energy input increases, powder melts more thoroughly forming a melt pool of liquid metal. The melt pool then solidifies, leading to full consolidation of the material. When the thermal energy that is delivered to the material is high, lighter elements evaporate causing bubbles to form in the melt pool. The bubble contains the working argon gas. When the melt pool solidifies, bubble walls will also solidify and manifest as gas porosity within the bulk material.

The volume fraction analysis results still show sample D3 having the lowest porosity at $0.07 \%$. Micro-CT results for samples C3, C4, D3 \& D4 (low porosity samples) show lower porosity values than that calculated through the area fraction analysis. Figure 5 shows the size, shape and distribution of the porosity in the samples. The results show that the porosity is randomly distributed within the samples. 

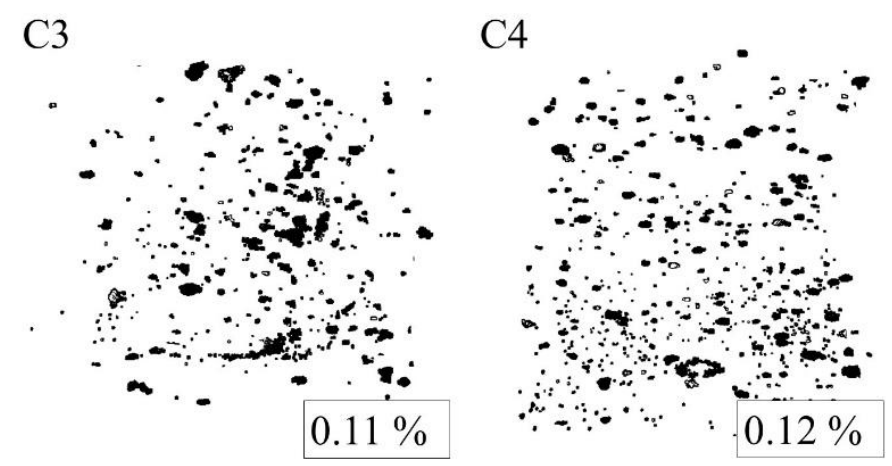

D3

D4
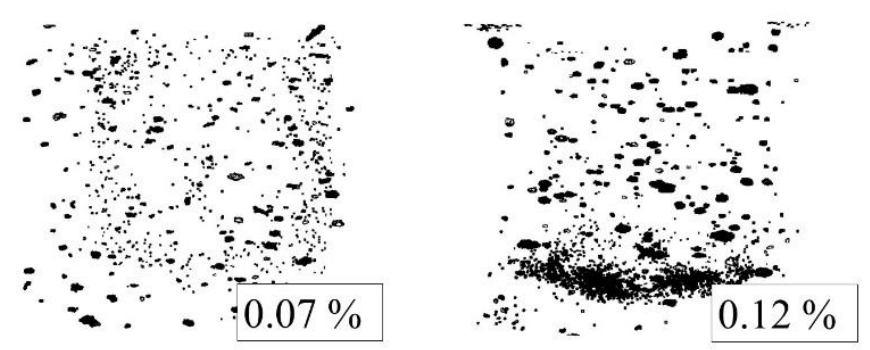

Figure 5: X-Ray micro-CT volumes showing morphology of the porosity within L-PBF IN718 samples

Difference between the two fraction measurement methods can be attributed to a few main factors. First, pore morphology is complex and heterogeneous and hence size and shape of pores at the free surface are different from those at the subsurface. The area fraction analysis is limited to free surface condition and hence approximates fraction based on the measurements of free surface. On the other hand, X-ray micro-CT method produces 3D pore shapes and sizes. Moreover, because the voxel size $4 \mu \mathrm{m}$ is used in X-ray micro-CT scans, pores smaller than 20 $\mu \mathrm{m}$ will not generally be detected which artificially decrease the measured porosity. Furthermore, the pixel size of the area fraction analysis is $0.64 \mu \mathrm{m}$ and in this case smaller pores can be detected. Hence, a combination of the characterisation methods is necessary to ascertain the correct percentage of porosity and its distribution within the samples.

\subsection{Texture analysis}

Figure 6 shows EBSD maps acquired from sample D3 (the lowest porosity sample) in the Z direction (a) and XY direction (b). Crystal orientation of a grain is shown as a colour value 
with the help of an inverse pole figure (IPF) legend. Black pixels are areas where the detector was unable to acquire crystal data and, in this instance, coincide with porosity in the sample.

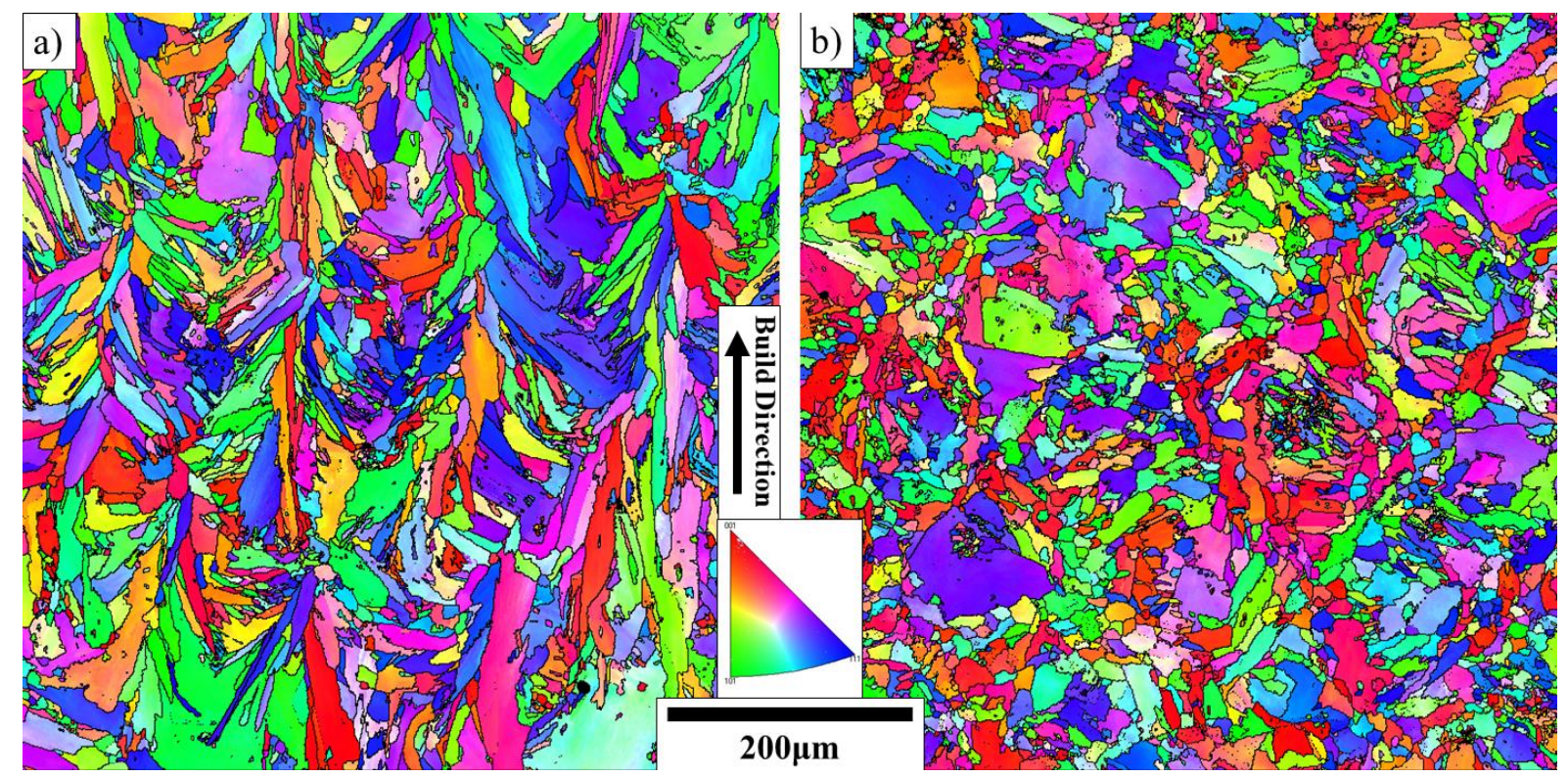

Figure 6: IPF coloured EBSD maps of sample D3; along the build direction (a) and XY direction $(b)$

EBSD maps reveal a significant difference in structure between $\mathrm{Z}$ and $\mathrm{XY}$ directions. Map (a) shows that most of the grains are columnar in shape. Numerous grains have their length running parallel to the $\mathrm{Z}$ direction and vary in length between 100-200 $\mu \mathrm{m}$. However, these columnar grains are not stacked together, one next to the other but are separated by areas where the grains are either, at a roughly $45^{\circ}$ angle to the $\mathrm{Z}$ direction, or areas of equiaxed small grains. In terms of crystal orientation, IPF colouring reveals that there is no preferred crystallographic direction. This type of microstructure is roughly columnar however it differs considerably from the columnar structure observed in IN718 processed by continuous L-PBF [40]. In prior work columnar grains have grown in an orderly fashion, one next to the other, and show a strong preference for the [001] crystallographic direction [40].

The microstructure the XY direction in Figure $6(\mathrm{~b})$ is distinguishably different from the $\mathrm{Z}$ direction. Most of the grains are irregular and small to medium in size $(5-40 \mu \mathrm{m}$ in diameter). Occasional very large (70-100 $\mu \mathrm{m}$ in length) grains that are roughly circular in shape can be 
observed. Therefore, it is possible to state that the microstructure at the XY plane is roughly equiaxed in nature. EBSD map data of the XY direction for IN718 processed using continuous L-PBF in the literature was not available, to the best knowledge of the authors. However, by studying of optical micrographs of etched samples [20] it is possible to extract information regarding the shape and size of grains in the $\mathrm{XY}$ direction for continuous L-PBF. This comparison reveals that pulsed L-PBF has a greater variation of grain sizes in contrast to continuous L-PBF [20].

The disparity in microstructure between pulsed and continuous L-PBF can be attributed to the difference in heat generation and subsequent cooling. The pulsed laser generates heat in a circular area surrounding the spot being illuminated creating a melt pool. After the end of the illumination the heated area quickly cools down at rates of $10^{4}$ to $10^{6} \mathrm{~K} / \mathrm{s}[41,42]$, possibly solidifying before the next point is illuminated. Hence discreet melt pools are created and extinguished. In contrast, the continuous laser energy input remains constant as it scans, leading to the formation of a melt pool which follows the laser, solidifying continuously.

It should be noted that other samples with high porosity in this study might not provide a representative grain morphology due to high porosity involvement. In addition, grain morphology will not dramatically change from one sample to the other in terms of columnar grain structure (Z direction) and equiaxed structure (XY direction).

\subsection{Tensile testing}

Tensile test results show that the pulsed L-PBF material in the as-built condition shows higher yield stress (YS) and ultimate tensile strength (UTS) than continuous L-PBF material in the asbuilt condition. However, tensile properties are lower than material produced through EB-PBF, both pulsed and continuous. The tensile testing results are presented in Table 4 along with data extracted from the literature regarding other PBF production methods, as well as for traditionally manufactured wrought IN718. 
Table 4: Summary of reported tensile properties of $L-P B F, E B-P B F$ and wrought IN718 material

\begin{tabular}{|c|c|c|c|c|c|}
\hline & Orientation & $\begin{array}{c}0.2 \% \text { YS } \\
(\mathrm{MPa})\end{array}$ & UTS (MPa) & $\begin{array}{c}\text { Young's } \\
\text { Modulus } \\
\text { (GPa) }\end{array}$ & $\begin{array}{c}\text { Elongation } \\
(\%)\end{array}$ \\
\hline \multirow{3}{*}{$\begin{array}{c}\text { Current } \\
\text { Study } \\
\text { (Pulsed L- } \\
\text { PBF) }\end{array}$} & Horizontal & $754.3 \pm 4.4$ & $1070.5 \pm 11.6$ & $216.5 \pm 3.7$ & $20.5 \pm 0.8$ \\
\hline & Vertical & $659.4 \pm 19.2$ & $1018.9 \pm 0.8$ & $211.5 \pm 4.7$ & $23.9 \pm 0.5$ \\
\hline & $45^{\circ}$ & $704.2 \pm 5.1$ & $1045.8 \pm 5$ & $213.4 \pm 2.7$ & $20.2 \pm 0.2$ \\
\hline \multirow{3}{*}{$\begin{array}{l}\text { Continuous } \\
\text { L-PBF [21] }\end{array}$} & Horizontal & $572 \pm 44$ & $904 \pm 22$ & $162 \pm 18$ & $19 \pm 4$ \\
\hline & Vertical & $643 \pm 63$ & $991 \pm 62$ & $193 \pm 24$ & $13 \pm 6$ \\
\hline & $45^{\circ}$ & $590 \pm 15$ & $954 \pm 10$ & $200 \pm 23$ & $20 \pm 1$ \\
\hline \multirow{2}{*}{$\begin{array}{c}\text { Pulsed EB- } \\
\text { PBF [26] }\end{array}$} & Horizontal & 850 & 1050 & \multirow{2}{*}{ N/A } & 22 \\
\hline & Vertical & 1000 & 1300 & & 15 \\
\hline EB-PBF [43] & Horizontal & $869 \pm 32$ & $1108 \pm 50$ & N/A & $22 \pm 1.8$ \\
\hline $\begin{array}{c}\text { Wrought } \\
\text { (Aged) [44] }\end{array}$ & N/A & 1034 & 1241 & 199 & 12 \\
\hline
\end{tabular}

Table 4 reveals that horizontal samples show higher yield stress (YS) and ultimate tensile strength (UTS) but lower elongation than the vertical samples. Samples produced at $45^{\circ}$ have YS and UTS values in between the other two types of samples but with similar elongation to horizontal samples. Differences in the tensile properties can be attributed to the difference observed in microstructure between $\mathrm{Z}$ and $\mathrm{XY}$ directions. In horizontal orientation samples, tensile stresses are applied along the transverse direction. Hence, the substantial number of grain boundaries help to increase strength of the material. In contrast, the vertical samples built vertically are loaded along the $\mathrm{Z}$ direction. The $\mathrm{Z}$ direction has a relatively small number of grain boundaries as well as these columnar types of elongated grains also possess dendritic 
featured microstructure. Hence, cracks and defects can propagate easier within the material leading to lowering the tensile properties for the vertical samples. Due to the above described explanation, it becomes apparent that the tensile properties of $45^{\circ}$ samples are in between the horizontal and the vertical samples. Moreover, there is no appreciable difference in elongation to failure amongst the samples built in various orientations.

Comparing the tensile test results of the current work with prior work in continuous L-PBF (Table 4) shows that using a pulsed laser source leads to improved mechanical properties regardless of the sample orientation. However, the effect of orientation on the mechanical properties is different in the two process paradigms. The difference in the tensile properties between pulsed and continuous samples can be explained by the marked difference between the $\mathrm{Z}$ direction microstructures produced by the two heat sources. Continuous L-PBF microstructure exhibits columnar grains along the $\mathrm{Z}$ direction [21] in contrast to pulsed L-PBF microstructure which is more 'complex' (Figure 6a). Hence, in horizontal orientation tensile testing, the grains can be pulled apart due to continuous L-PBF microstructure which is not the case for pulsed L-PBF microstructure.

While comparing tensile properties of the current study to EB-PBF (Table 4), horizontal samples showed similar results in terms of UTS and elongation. In contrast, the results of pulsed EB-PBF show comparable results for the horizontal orientation but markedly better properties for pulsed EB-PBF samples in the vertical orientation. However, it should be noted that the scanning strategy employed in [26] was specifically designed to take advantage of the pulsing nature of the heat source.

\subsection{Incremental hole drilling residual stress measurements}

Figure 7 shows the incremental hole drilling residual stresses measurement data for the specimens with support structures (a) and without support structures (b). The hole depth reached from the top surface of each specimen, varied from $0.96 \mathrm{~mm}$ to $1.02 \mathrm{~mm}$. Hence, the 
repeatability of the hole drilling procedure isn't identical despite the specimens being produced using the same process parameters. This lack of repeatability is demonstrated in the two charts showing that each specimen has a slightly different residual stress field, whether it is supported or not. For the supported specimens, $\sigma_{\mathrm{xx}}$ and $\sigma_{\mathrm{yy}}$ stress components are tensile in nature and range from $0 \mathrm{MPa}$ to $463 \mathrm{MPa}$ with increased hole depth. The shear stress component $\tau_{\mathrm{xy}}$ is slightly tensile at small depths and becomes more compressive deeper in the hole varying from 33.6 MPa to -42 MPa. For the specimens without supports, $\sigma_{\mathrm{xx}}$ and $\sigma_{\mathrm{yy}}$ stress components varied from slightly compressive to tensile and values of $-6.5 \mathrm{MPa}$ to $159 \mathrm{MPa}$ without a strong correlation with hole depth. Shear stress component $\tau_{\mathrm{xy}}$ begins as compressive for specimens 4 and 5 and becomes tensile with increased hole depth from -56 MPa to $11 \mathrm{MPa}$. Shear stress component for specimen 6 however reverses the trend for unsupported specimens because it becomes more compressive with increased hole depth instead of tensile. 
a)

\section{Residual Stress versus Hole Depth - Supports}

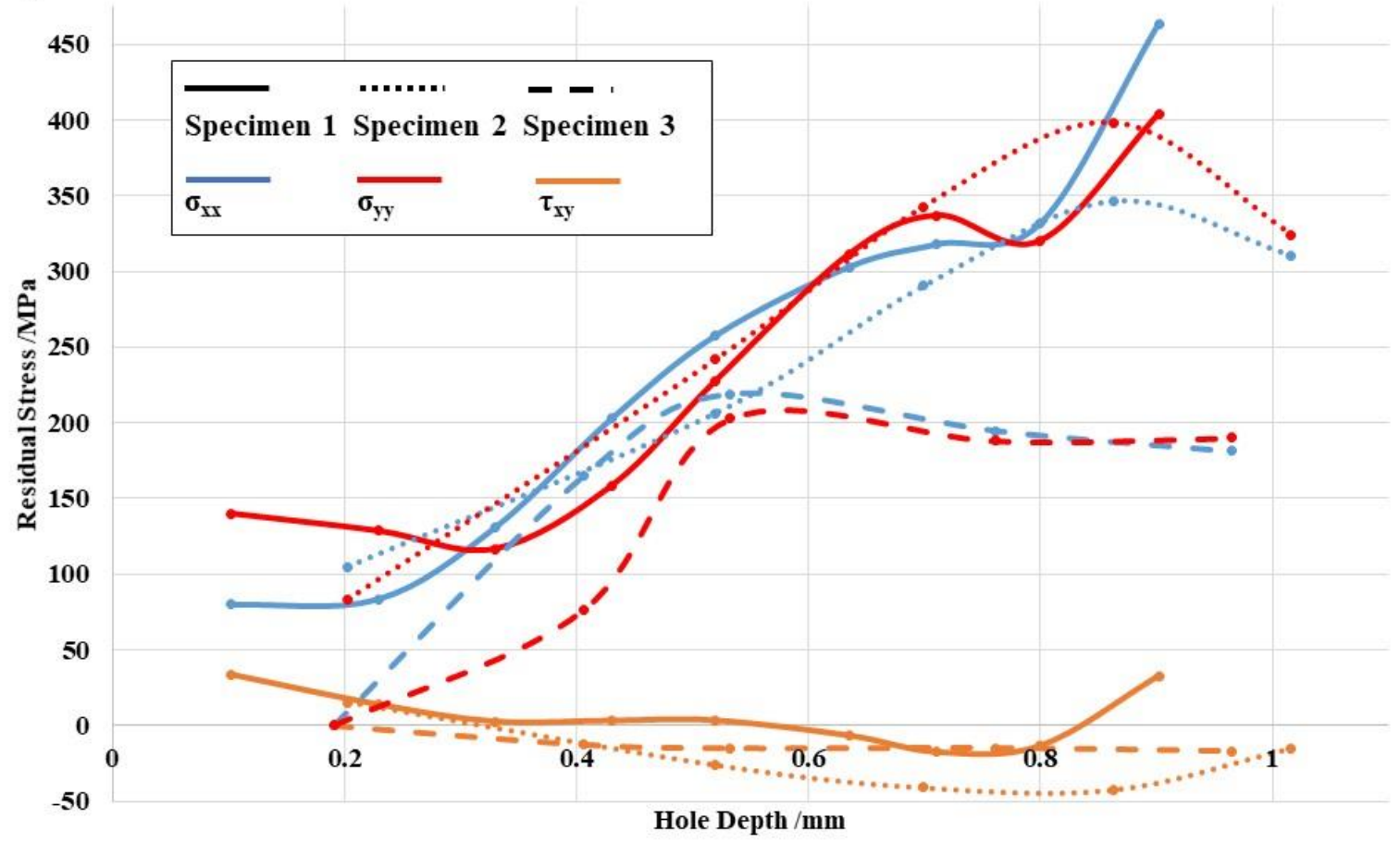

b) Residual Stress versus Hole Depth - No Supports

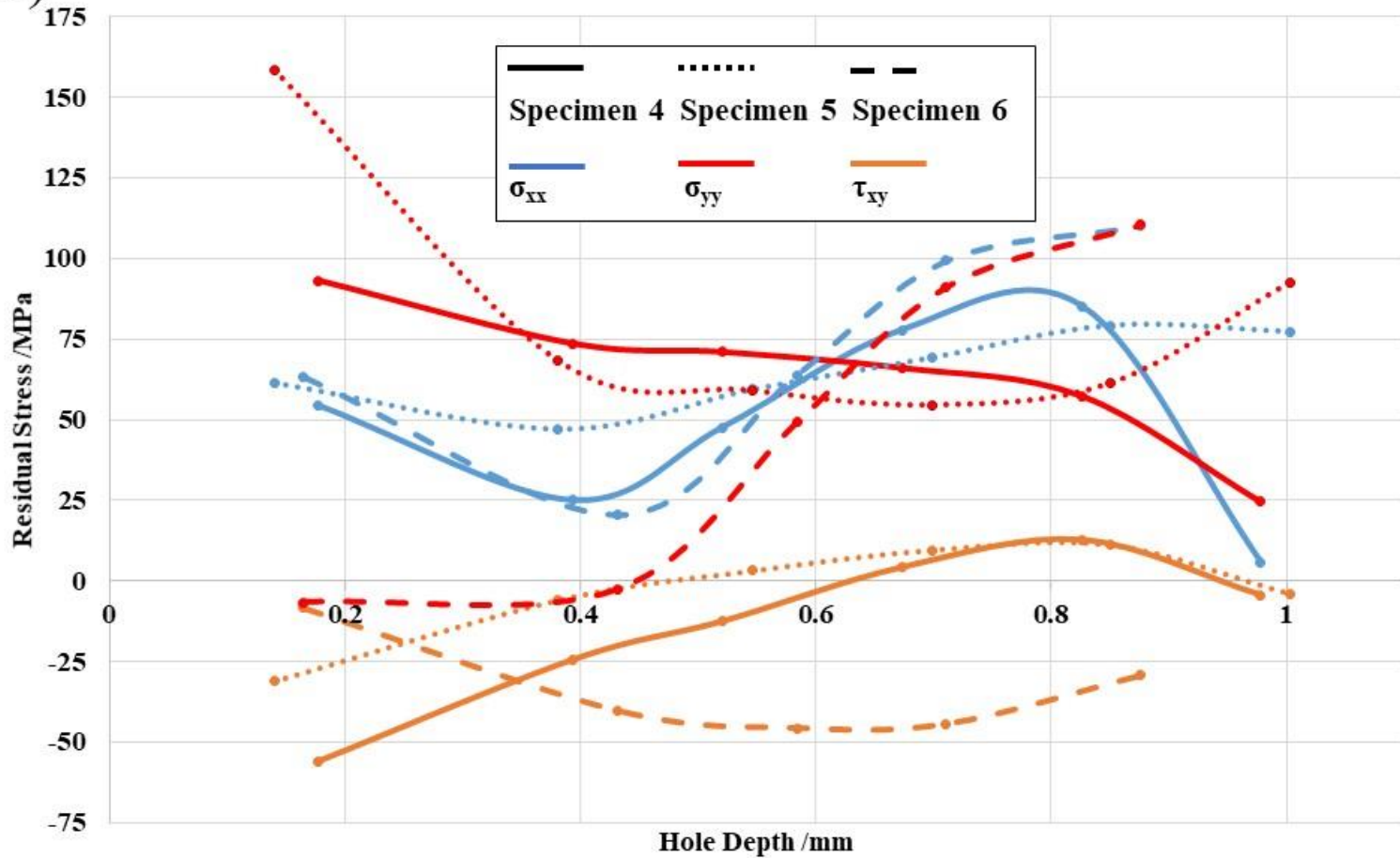

Figure 7: Residual stresses measurements for L-PBF IN718 samples with (a) and without supports (b) 
Despite each specimen exhibiting a different residual stress field, general tendencies can be seen for each type of specimens (supported versus unsupported). The supported specimens show increasing tensile stress for the $\sigma_{\mathrm{xx}}$ and $\sigma_{\mathrm{yy}}$ components, with increased hole depth. The two stress components are closely related to each other, both following the same trend. Specimens 2 and 3 showed a maximum being reached followed by a slight decrease in the magnitude of the stress. However, the depth at which this change-over occurs varies from 0.53 $\mathrm{mm}$ for specimen 3 to $0.86 \mathrm{~mm}$ for specimen 2 . In contrast specimen 1 shows continuous increase with increasing hole depth, with no discernible change-over point. The shear stress component $\tau_{\mathrm{xy}}$ for all three specimens shows a change from slightly tensile shear to compressive shear with increasing hole depth.

For the specimens without supports, the normal stress components $\left(\sigma_{\mathrm{xx}} \& \sigma_{\mathrm{yy}}\right)$ do not exhibit any discernible behaviour with increased hole depth. The shear stress component $\tau_{\mathrm{xy}}$ for specimens 4 and 5 show a change from compressive to slightly tensile with increased hole depth. Conversely, shear stress for specimen 6 becomes more compressive with increased hole depth.

Residual stress data showed that specimens without supports exhibit lower residual stresses in comparison to those with supports. Prior research has shown that this is expected [45] for two main reasons. Specimens without supports are built directly on top of the substrate plate and share a large interface with it. Hence, any residual stress that develops in the specimens is counteracted in part by the substrate. Therefore, the removal of the specimens from the substrate leads to a release of residual stress, leading to a reduction in measured residual stress. Residual stress data also show that the normal residual stress components $\left(\sigma_{\mathrm{xx}} \& \sigma_{\mathrm{yy}}\right)$ are significantly higher than the shear component $\left(\tau_{\mathrm{xy}}\right)$ and roughly equal. This occurs due to the pulsed nature of the heating-cooling cycle as well as due to the rotation of the scan lines between subsequent layers, during the manufacturing. 
There are certain issues with the hole drilling residual stress measurement method as performed on L-PBF material. The existence of porosity within the L-PBF specimens affects the residual stress field. Therefore, random distribution of the porosity, despite the same parameters used for manufacturing, will produce different residual stress fields for each specimen. These random stress fields impact the reproducibility of the hole drilling measurement which makes it very difficult for a direct quantitative comparison between specimens. However, qualitative comparisons are easier to make with obvious trends being exhibited in the case of the specimens with and without supports.

Note that it may be possible to relieve residual stresses during manufacturing by means of base plate pre-heating, However, the results presented in this study were obtained without the preheating case and hence residual stresses are to be larger than expected for the pre-heating case.

\section{Conclusions}

In this study, several aspects of pulsed L-PBF manufacturing of IN718 material were investigated. These were; characterisation of the precursor powder, determination of pulsed LPBF process parameters to fabricate highly dense material, assessment of tensile properties and residual stress measurement in the as-built condition. The following conclusions can be drawn from this work:

- AGA IN718 powder with a PSD of $29-52 \mu \mathrm{m}$, a Hausner ratio of 1.17 and typical gas atomised morphology has been found suitable for the pulsed L-PBF process.

- Area fraction analysis shows porosity reaches a minimum of $0.16 \%$. Hence $99.84 \%$ dense material can be achieved for pulsed L-PBF process parameters of $200 \mathrm{~W}$ for the laser power and $110 \mu$ s for the exposure time and is comparable to the density achieved by continuous LPBF. 
- Crystal structure of the as-built pulsed L-PBF IN718 material is less oriented and less columnar than continuous L-PBF.

- Resultant grain structure of pulsed L-PBF samples in the 'as built' condition show a YS of $\sim 706 \mathrm{MPa}$, a UTS of $\sim 1045 \mathrm{MPa}$ and elongation of $\sim 21.5 \%$ on average.

- There is no distinguishable difference between pulsed and continuous L-PBF in elongation of IN718.

- It is possible to produce stronger and slightly stiffer IN718 by means of pulsed L-PBF in comparison with continuous L-PBF without having to sacrifice ductility.

- Maximum residual stress in the samples with support structures is $463 \mathrm{MPa}$, three time higher than in samples without support structures at $159 \mathrm{MPa}$.

Funding: This publication was made possible by the sponsorship and support of Lloyd's Register Foundation. The work was enabled through, and undertaken at, the National Structural Integrity Research Centre (NSIRC), a postgraduate engineering facility for industry-led research into structural integrity established and managed by TWI through a network of both national and international Universities. Lloyd's Register Foundation helps to protect life and property by supporting engineering-related education, public engagement and the application of research.

Data availability: The raw data required to reproduce these findings cannot be shared at this time as the data also forms part of an ongoing study. The processed data required to reproduce these findings cannot be shared at this time as the data also forms part of an ongoing study.

\section{References}

[1] ISO, Additive manufacturing — General principles — Terminology, ISO/ASTM 52900. (2015) 1-26. doi:10.1520/F2792-12A.2.

[2] I. Campbell, O. Diegel, J. Kowen, T. Wohlers, Wohlers Report 2017 3D Printing and 
Additive Manufacturing State of the Industry Annual Worldwide Progress Report, Fort Collins, 2017.

[3] J.O. Milewski, Additive Manufacturing of Metals: From Fundamental Technology to Rocket Nozzles, Medical Implants, and Custom Jewelry, Springer International Publishing, 2017. doi:10.1007/978-3-319-58205-4.

[4] L.N. Carter, X. Wang, N. Read, R. Khan, M. Aristizabal, K. Essa, M.M. Attallah, Process optimisation of selective laser melting using energy density model for nickel based superalloys, Mater. Sci. Technol. 32 (2016) 1-5. doi:10.1179/1743284715Y.0000000108.

[5] M. Valdez, C. Kozuch, E.J. Faierson, I. Jasiuk, Induced porosity in Super Alloy 718 through the laser additive manufacturing process : Microstructure and mechanical properties, J. Alloys Compd. 725 (2017) 757-764. doi:10.1016/j.jallcom.2017.07.198.

[6] H. Gu, H. Gong, P. Deepankar, R. Khalid, S. Thomas, B. Stucker, Influences of Energy Density on Porosity and Microstructure of Selective Laser Melted 17-4PH Stainless Steel, in: 24th Annu. Int. Solid Free. Fabr. Symp., 2013: pp. 474-489.

[7] M. Iebba, A. Astarita, D. Mistretta, I. Colonna, M. Liberini, F. Scherillo, C. Pirozzi, R. Borrelli, S. Franchitti, A. Squillace, Influence of Powder Characteristics on Formation of Porosity in Additive Manufacturing of Ti-6Al-4V Components, J. Mater. Eng. Perform. 26 (2017) 1-10. doi:10.1007/s11665-017-2796-2.

[8] Y. Liu, Y. Yang, D. Wang, A study on the residual stress during selective laser melting (SLM) of metallic powder, Int. J. Adv. Manuf. Technol. (2016) 1-10. doi:10.1007/s00170-016-8466-y.

[9] L.M. Sochalski-Kolbus, E.A. Payzant, P.A. Cornwell, T.R. Watkins, S.S. Babu, R.R. Dehoff, M. Lorenz, O. Ovchinnikova, C. Duty, Comparison of Residual Stresses in Inconel 718 Simple Parts Made by Electron Beam Melting and Direct Laser Metal 
Sintering, Metall. Mater. Trans. A Phys. Metall. Mater. Sci. 46 (2015) 1419-1432. doi:10.1007/s11661-014-2722-2.

[10] R.J. Moat, A.J. Pinkerton, L. Li, P.J. Withers, M. Preuss, Residual stresses in laser direct metal deposited Waspaloy, Mater. Sci. Eng. A. 528 (2011) 2288-2298. doi:10.1016/j.msea.2010.12.010.

[11] W.J. Sames, F.A. List, S. Pannala, R.R. Dehoff, S.S. Babu, The metallurgy and processing science of metal additive manufacturing, Int. Mater. Rev. 61 (2016) 315360. doi:10.1080/09506608.2015.1116649.

[12] Y. Kok, X.P. Tan, P. Wang, M.L.S. Nai, N.H. Loh, E. Liu, S.B. Tor, Anisotropy and heterogeneity of microstructure and mechanical properties in metal additive manufacturing: A critical review, Mater. Des. 139 (2018) 565-586. doi:10.1016/j.matdes.2017.11.021.

[13] H. Ali, L. Ma, H. Ghadbeigi, K. Mumtaz, In-situ residual stress reduction, martensitic decomposition and mechanical properties enhancement through high temperature powder bed pre-heating of Selective Laser Melted Ti6Al4V, Mater. Sci. Eng. A. 695 (2017) 211-220. doi:http://doi.org/10.1016/j.msea.2017.04.033.

[14] A. Riemer, H.A. Richard, J.P. Brüggemann, J.N. Wesendahl, Fatigue crack growth in additive manufactured products, Frat. Ed Integrita Strutt. 9 (2015) 437-446. doi:10.3221/IGF-ESIS.34.49.

[15] R.C. Reed, The Superalloys, Fundamentals and Applications, Cambridge University Press, Cambridge, 2006.

[16] M.J. Donachie, S.J. Donachie, Superalloys: A Technical Guide, 2nd ed., ASM International, Materials Park, OH, 2002.

[17] A. Mostafa, I. Picazo Rubio, V. Brailovski, M. Jahazi, M. Medraj, Structure, Texture and Phases in 3D Printed IN718 Alloy Subjected to Homogenization and HIP 
Treatments, Metals (Basel). 7 (2017) 196. doi:10.3390/met7060196.

[18] D. Lambert, M. Adler, IN718 Additive Manufacturing Properties and Influences, Addit. Manuf. Consort. Meet. (2014) 1-23. http://ntrs.nasa.gov/search.jsp?R=20140016887.

[19] J. Strößner, M. Terock, U. Glatzel, Mechanical and Microstructural Investigation of Nickel-Based Superalloy IN718 Manufactured by Selective Laser Melting (SLM), Adv. Eng. Mater. 17 (2015) 1099-1105. doi:10.1002/adem.201500158.

[20] K.N. Amato, S.M. Gaytan, L.E. Murr, E. Martinez, P.W. Shindo, J. Hernandez, S. Collins, F. Medina, Microstructures and mechanical behavior of Inconel 718 fabricated by selective laser melting, Acta Mater. 60 (2012) 2229-2239. doi:10.1016/j.actamat.2011.12.032.

[21] E. Chlebus, K. Gruber, B. Kuznicka, J. Kurzac, T. Kurzynowski, Effect of heat treatment on the microstructure and mechanical properties of Inconel 718 processed by selective laser melting, Mater. Sci. Eng. A. 639 (2015) 647-655. doi:10.1016/j.msea.2015.05.035.

[22] V.A. Popovich, E.V. Borisov, A.A. Popovich, V.S. Sufiiarov, D.V. Masaylo, L. Alzina, Functionally graded Inconel 718 processed by additive manufacturing: Crystallographic texture, anisotropy of microstructure and mechanical properties, Mater. Des. 114 (2017) 441-449. doi:10.1016/j.matdes.2016.10.075.

[23] A.J. Pinkerton, [INVITED] Lasers in additive manufacturing, Opt. Laser Technol. 78 (2016) 25-32. doi:10.1016/j.optlastec.2015.09.025.

[24] A.G. Demir, P. Colombo, B. Previtali, From pulsed to continuous wave emission in SLM with contemporary fiber laser sources: effect of temporal and spatial pulse overlap in part quality, Int. J. Adv. Manuf. Technol. 91 (2017) 2701-2714. doi:10.1007/s00170-016-9948-7. 
[25] R.R. Dehoff, M.M. Kirka, W.J. Sames, H. Bilheux, A.S. Tremsin, L.E. Lowe, S.S. Babu, Site specific control of crystallographic grain orientation through electron beam additive manufacturing, Mater. Sci. Technol. 31 (2015) 931-938.

doi:10.1179/1743284714Y.0000000734.

[26] M.M. Kirka, Y. Lee, D.A. Greeley, A. Okello, M.J. Goin, M.T. Pearce, R.R. Dehoff, Strategy for Texture Management in Metals Additive Manufacturing, JOM. 69 (2017) 523-531. doi:10.1007/s11837-017-2264-3.

[27] S.C. Chou, M. Trask, J. Danovitch, X.L. Wang, J.P. Choi, M. Brochu, Pulsed laser powder bed fusion additive manufacturing of A356, Mater. Charact. 143 (2018) 2733. doi:10.1016/j.matchar.2018.02.004.

[28] Q. Huang, X. Liu, X. Yang, R. Zhang, Z. Shen, Q. Feng, Speci fi c heat treatment of selective laser melted $\mathrm{Ti}-6 \mathrm{Al}-4 \mathrm{~V}$ for biomedical applications, 9 (2015) 373-381. doi:10.1007/s11706-015-0315-7.

[29] ISO, ISO 7524:1985 Nickel, ferronickel and nickel alloys — Determination of carbon content — Infra-red absorption method after induction furnace combustion, (1985). Www.iso.org.

[30] ISO, ISO 7525:1985 Nickel — Determination of sulfur content - Methylene blue molecular absorption spectrometric method after generation of hydrogen sulfide, (1985). www.iso.org.

[31] ASTM International, ASTM B822 - 17 Standard Test Method for Particle Size Distribution of Metal Powders and Related Compounds by Light Scattering, (2017). doi:10.1520/B0822-17.

[32] ASTM International, ASTM B213 - 17 Standard Test Methods for Flow Rate of Metal Powders Using the Hall Flowmeter Funnel, (2017). doi:10.1520/B0213-17.

[33] ASTM International, ASTM B212 - 17 Standard Test Method for Apparent Density of 
Free-Flowing Metal Powders Using the Hall Flowmeter Funnel, (2017). doi:10.1520/B0212-17.

[34] ASTM International, ASTM B527 - 15 Standard Test Method for Tap Density of Metal Powders and Compounds, (2015). doi:10.1520/B0527-15.

[35] ASTM International, ASTM E2109 - 01(2014) Standard Test Methods for Determining Area Percentage Porosity in Thermal Sprayed Coatings, (2014). doi:10.1520/E2109-01R14.

[36] M.E. Kartal, L.H. Dugdale, J.J. Harrigan, M.A. Siddiq, D. Pokrajac, D.M. Mulvihill, Three-dimensional in situ observations of compressive damage mechanisms in syntactic foam using X-ray microcomputed tomography, J. Mater. Sci. 52 (2017) 10186-10197. doi:10.1007/s10853-017-1177-4.

[37] ASTM International, ASTM E8-16a Standard Test Methods for Tension Testing of Metallic Materials, (2016). doi:10.1520/E0008_E0008M-16A.

[38] G.S. Schajer, Measurement of Non-Uniform Residual Stresses Using the Hole-Drilling Method. Part I—Stress Calculation Procedures, J. Eng. Mater. Technol. 110 (1988) 338. doi:10.1115/1.3226059.

[39] M.J. Matthews, G. Guss, S.A. Khairallah, A.M. Rubenchik, P.J. Depond, W.E. King, Denudation of metal powder layers in laser powder bed fusion processes, Acta Mater. 114 (2016) 33-42. doi:10.1016/j.actamat.2016.05.017.

[40] X. Wang, K. Chou, Effects of thermal cycles on the microstructure evolution of Inconel 718 during selective laser melting process, Addit. Manuf. 18 (2017) 1-14. doi:10.1016/j.addma.2017.08.016.

[41] W.E. Frazier, Metal Additive Manufacturing: A Review, J. Mater. Eng. Perform. 23 (2014) 1917-1928. doi:10.1007/s11665-014-0958-z.

[42] M. Masoomi, S.M. Thompson, N. Shamsaei, Laser powder bed fusion of Ti-6Al-4V 
parts : Thermal modeling and mechanical implications, Int. J. Mach. Tools Manuf. 118-119 (2017) 73-90. doi:10.1016/j.ijmachtools.2017.04.007.

[43] W.J. Sames, K.A. Unocic, G.W. Helmreich, M.M. Kirka, F. Medina, R.R. Dehoff, S.S. Babu, Feasibility of in situ controlled heat treatment (ISHT) of Inconel 718 during electron beam melting additive manufacturing, Addit. Manuf. 13 (2016) 1-10. doi:10.1016/j.addma.2016.09.001.

[44] Special Metals, INCONEL alloy 718, (2007) 1-28. doi:SMC-066.

[45] A. Salmi, E. Atzeni, L. Iuliano, M. Galati, Experimental Analysis of Residual Stresses on AlSi10Mg Parts Produced by Means of Selective Laser Melting (SLM), Procedia CIRP. 62 (2017) 458-463. doi:10.1016/j.procir.2016.06.030. 